Vincent W. S. Chan FrCPC, Frances Chung FrCPC, Davy C. H. Cheng FRCPC, Chanth Seyone MD, Alan Chung MBBS, Thomas J. Kirby FRCSC

\title{
Analgesic and pulmonary effects of continuous intercostal nerve block following thoracotomy
}

\begin{abstract}
This study examined the beneficial effects and potential systemic toxicity from continuous intercostal nerve block by repeated bolus injections of bupivacaine. In this double-blind, randomized study, 20 post-thoracotomy patients were assigned to receive four doses of either: $20 \mathrm{ml} 0.5 \%$ bupivacaine with epinephrine $5 \mu \mathrm{g} \cdot \mathrm{ml}^{-1}$ (bupivacaine group, $n=10$ ), or $20 \mathrm{ml}$ preservative-free saline (placebo group, $n=10$ ) through two indwelling intercostal catheters every six hours. Patients receiving intercostal bupivacaine injections had greater decreases in visual analogue pain scores (VAS) $(P<0.05)$ and lower $24 \mathrm{hr}$ morphine requirements, $16.6 \pm 4.6 \mathrm{mg}$ vs $35.8 \pm 7.2 \mathrm{mg}$, than patients in the placebo group $(P<0.05)$. Higher post-injection values of forced expiratory volume in one second, forced vital capaciry and peaked expiratory flow rate were also observed in the bupivacaine group $(P<0.01)$. Repeated intercostal bupivacaine administration did lead to systemic accumulation, but the peak bupivacaine level after $400 \mathrm{mg}$ was low at $1.2 \pm 0.2$ $\mu \mathrm{g} \cdot \mathrm{ml}^{-1}$. Thus, the technique of continuous intercostal nerve block described in this study is an effective treatment for the control of post-thoracotomy pain.
\end{abstract}

Cette étude examine les effets bénéfiques et la toxicité systémique potentielle d'un bloc nerveux intercostal continu par des injections répétées de bupivacaine. Dans celte étude randomi-

\section{Key words}

ANAESTHETICS, LOCAL: bupivacaine;

ANAESTHETIC TECHNIQUES: regional, intercostal; PAIN: postoperative.

From the Departments of Anaesthesia and Surgery, Toronto Western Division, The Toronto Hospital, University of Toronto, Toronto, Ontario, Canada M5T 2S8.

Address correspondence 10: Dr Vincent Chan, Department of Anaesthesia, Toronto Western Division, The Toronto Hospital, 399 Bathurst Street, Toronto, Ontario, Canada M5T 2S8.

Supported in part by a grant from Winthrop Pharma.

Accepted for publication 17th April, 1991. sée chaque six heures d̀ double insu, 20 patients post-thoracotomie ont été divisés afin de recevoir quatre doses de soit : $20 \mathrm{ml} 0,5 \%$ de bupivacaïne avec épinéphrine $5 \mu \mathrm{g} \cdot \mathrm{ml}^{-1}$ (groupe bupivacaine, $n=10$ ), ou $20 \mathrm{ml}$ de soluré physiologique sans préservatif (groupe placébo, $n=10$ ) via un cathéter intercostal chaque six heures. Les patients recevant des injections de bupivacaine intercostal ont démontré une plus grande diminution dans le test du "Visual analogue pain scores (VAS) $(P<0.05)$ " et ont requis en 24 heures moins de morphine, 16,6 $\pm 4,6 \mathrm{mg}$ vs 35,8 $\pm 7,2 \mathrm{mg}$ que les patients du groupe placebo $(P<0.05)$. Les valeurs post-injection plus élevées étaient notées dans le $F E V_{1}$, la capacité vitale forcée et le flot expiratoire maximal pour le groupe bupivacaine $(P<0.01)$. L'administration répétée de bupivacaine intercostale a amené une accumulation systémique mais le niveau maximal de bupivacaïne après $400 \mathrm{mg}$ était bas à $1,2 \pm 0,2 \mu \mathrm{g} \cdot \mathrm{ml}^{-1}$. Ainsi, la rechnique du bloc nerveux intercostal continu décrite dans celte étude fut un moyen thérapeutique efficace pour le contróle de la douleur post-thoracotomie.

For many years before the use of spinal opioids, intercostal nerve block was the standard of effective regional analgesia following thoracotomy incisions. ${ }^{1.2}$ Its popularity continues because it is simple to perform, and lacks many of the potential side-effects of spinal opioids: respiratory depression, pruritus and urinary retention. Although effective, analgesia after a single intercostal nerve block is limited by the duration of the local anaesthetic activity. To achieve prolonged pain relief, a percutaneous continuous intercostal nerve block technique has been described. ${ }^{3}$ This technique has been applied effectively to control pain following upper abdominal incisions, ${ }^{4}$ sternotomy, ${ }^{5}$ rib fractures ${ }^{3,6}$ and thoracotomy. ${ }^{7}$ In the case of thoracotomy incision, it is conceivable that a simple intrathoracic approach to posterior intercostal catheterization be used as the thoracic cavity is open to direct inspection. Among the regional blocks commonly practiced, intercostal nerve block 
results in the highest systemic local anaesthetic absorption. With the continuous injection technique, the potential for local anaesthetic toxic reaction needs to be addressed.

The purpose of this study was to examine the usefulness of an alternative intrathoracic method of continuous intercostal nerve block in the control of post-thoracotomy pain, its effect on postoperative lung function and the degree of systemic bupivacaine accumulation after repeated intercostal injections.

\section{Methods}

Twenty ASA physical status II and III patients, aged 44-81 yr, gave informed consent to participate in this prospective double-blind study, as approved by the Human Research Committee of Toronto Western Division, The Toronto Hospital. Patients with known local anaesthetic hypersensitivity, renal and hepatic diseases, were excluded. Elective thoracotomies were performed by the same thoracic surgeon for the following procedures: lobectomy $(n=13)$, wedge resection $(n=2)$ and trans-thoracic oesophageal surgery $(n=5)$. All thoracotomy incisions were made in the posterior fifth intercostal spaces, starting at the axilla and ending at the midpoint between the scapula and thoracic spine. All patients received general anaesthesia: premedication with $5-10 \mathrm{mg}$ diazepam one hour before surgery, induction with thiopentone, intubation with double lumen tube following succinylcholine and maintenance with pancuronium, nitrous oxide, oxygen and a volatile inhalational agent (isoflurane or enflurane). Intraoperative fentanyl administration was limited to $2 \mu \mathrm{g} \cdot \mathrm{kg}^{-1}$ at the time of skin incision and then $1 \mu \mathrm{g} \cdot \mathrm{kg}^{-1}$ every hour as necessary, judged by the patient's haemodynamic response to surgical stimulation. Intraoperative monitoring included radial arterial catheter for blood pressure and blood gas measurements, ECG, pulse oximeter, temperature, peripheral nerve stimulator and mass spectrometer indicating endtidal carbon dioxide.

At the completion of the surgical procedure and before wound closure, the surgeon gently peeled back the parietal pleura from the ribs at the incision site. A 20-gauge Portex epidural catheter was tunnelled subpleurally under direct vision, $7-8 \mathrm{~cm}$ lateral to the vertebral column. The catheter was placed perpendicular to the ribs and $4-5 \mathrm{~cm}$ deep to reach a posterior intercostal space just below the incision site (Figure 1). In the same manner, a second intercostal catheter was placed just above the incision site. The final position of the two catheters in the posterior intercostal spaces was verified both visually and by palpation. The remaining portion of each catheter was then loosely sutured in place on the parietal pleura before making their exits through the chest
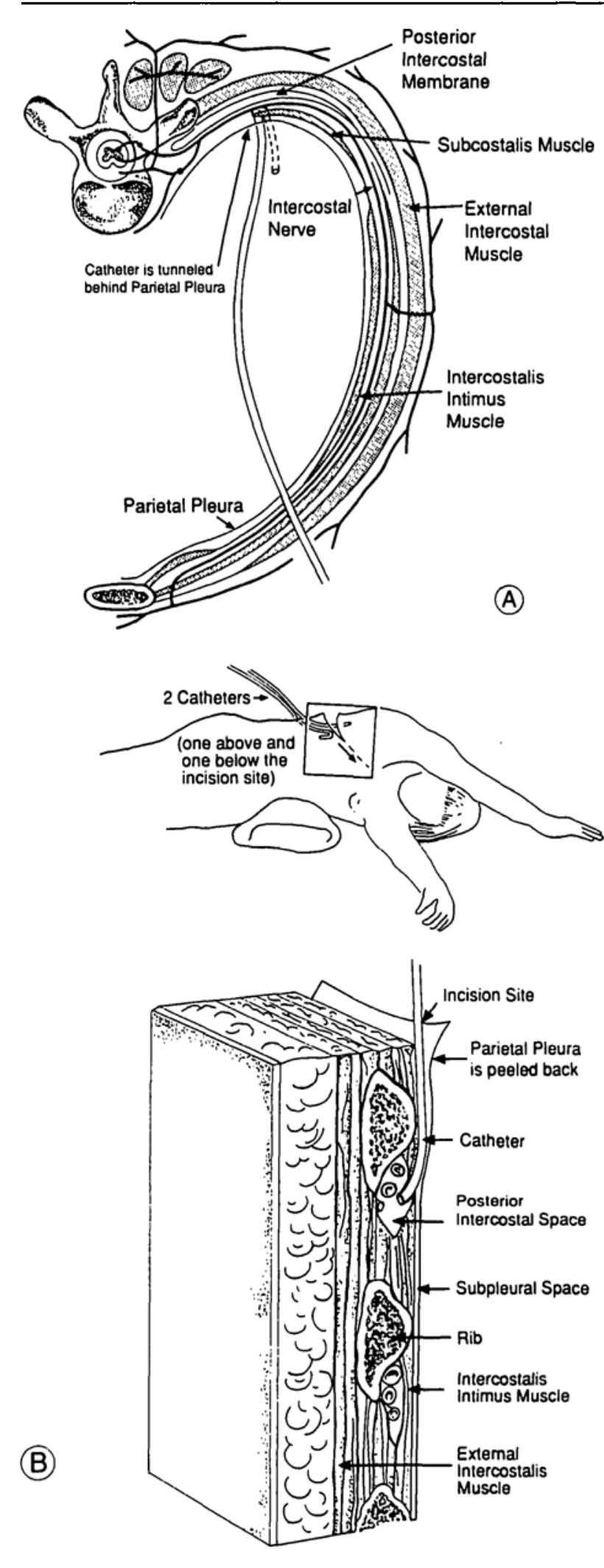

FIGURE I(A, B) Technique and site of intercostal catheter placement. 
TABLE I Demographic data and intraoperative fentanyl consumplion

\begin{tabular}{lcc}
\hline & $\begin{array}{l}\text { Bupivacaine group } \\
(n=10\end{array}$ & $\begin{array}{l}\text { Placebo group } \\
(n=10)\end{array}$ \\
\hline Age & $63.6 \pm 3.86$ & $59.1 \pm 2.42$ \\
Sex & M:7 F:3 & M:7 F:3 \\
Height $(\mathrm{cm})$ & $162.3 \pm 2.43$ & $169.7 \pm 2.97$ \\
Weight $(\mathrm{kg})$ & $69.6 \pm 4.18$ & $64.7 \pm 3.40$ \\
Duration of surgery (min) & $198.3 \pm 13.82$ & $223.5 \pm 23.52$ \\
Intraoperative fentanyl $(\mu \mathrm{g})$ & $200.0 \pm 26.70$ & $328.1 \pm 63.29$ \\
\hline
\end{tabular}

Mean \pm SEM.

wall near the chest tube site. The extra-thoracic ends were used for repeated intercostal injections.

In this double-blind protocol, patients were randomly assigned to one of two groups: bupivacaine or placebo group. Ten patients in the bupivacaine group received $100 \mathrm{mg}$ of $0.5 \%$ bupivacaine with $1 / 200,000$ epinephrine, i.e., $10 \mathrm{ml}$ through each of the two catheters over two to three minutes after a negative aspiration test for blood. Patients, nurses, anaesthetists and investigators were all blinded to the type of solution for injection. For the placebo group, $10 \mathrm{ml}$ of preservative-free saline were injected into each catheter. All patients were awake, extubated and monitored in the intensive care unit during injections. Three subsequent top-up doses, using the same dose and solution, were given to each group at six hourly intervals for $24 \mathrm{hr}$. A total of $400 \mathrm{mg}$ bupivacaine was given in the bupivacaine group. Postoperative patient monitoring of systolic and diastolic blood pressure, heart rate, and respiratory rate was carried out every hour for the first eight hours and, in particular, vital signs were checked every ten minutes for $30 \mathrm{~min}$ after each intercostal injection.

Serial assessments of pain intensity and pulmonary function were initiated following the first intercostal injection. Assessments were not performed prior to the first intercostal injection because a lack of patient cooperation was anticipated during the immediate postanaesthetic period when patients awoke with intense pain. In each patient, visual analogue pain scores (VAS: $10 \mathrm{~cm}$ line with the left end labeled "No pain" and the right end labeled "Severe pain") were evaluated ten minutes before and one hour after each subsequent injection. Bedside pulmonary function tests of forced expiratory volume in one second $\left(F E V_{1}\right)$, forced vital capacity $(F V C)$ and peak expiratory flow rate (PEFR) by a portable compact spirometer (Vitalograph Ltd., Buckingham, England) were carried out in each patient at a $45^{\circ}$ sitting angle preoperatively, one hour before and one hour after each injection.

To guarantee satisfactory analgesia, patients were instructed to request supplemental intravenous morphine from nurses who would administer repeated doses of 0.06 $\mathrm{mg} \cdot \mathrm{kg}^{-1}$ every $15-30 \mathrm{~min}$ upon request. Details of morphine utilization in $24 \mathrm{hr}$ were recorded and compared between the two groups. No other sedative medications were permitted.

Arterial blood in $3 \mathrm{ml}$ aliquots, was obtained from indwelling radial artery catheters in 18 patients at $0,2.5$, $5,10,20$ and 60 min after each of the four injections. Blood samples were centrifuged immediately to separate the plasma which was then frozen at $-20^{\circ} \mathrm{C}$. To assess the extent of local anaesthetic systemic absorption, the bupivacaine concentration was determined in blood samples of nine patients by gas chromatography. ${ }^{8}$ Plasma bupivacaine concentration is reported as $\mu \mathrm{g}$ bupivacaine $\mathrm{HCl} \cdot \mathrm{ml}^{-1}$. The coefficient of variation of this assay was $10 \%$ at $0.1 \mu \mathrm{g} \cdot \mathrm{ml}^{-1}$ and $5 \%$ at $1.00 \mu \mathrm{g} \cdot \mathrm{ml}^{-1}$. Mean peak bupivacaine concentration $\left(\mathrm{C}_{\max }\right)$ and mean time to peak concentration $\left(\mathrm{T}_{\max }\right)$ were calculated.

\section{Statistical analysis}

Data are presented as mean values \pm SEM. Continuous variables, i.e., visual analogue pain score, pulmonary function tests, morphine consumption and plasma bupivacaine concentration were compared within and between groups using Student's $t$ tests, one way analysis of variance (ANOVA) for repeated measures and multiple regression analysis where appropriate. Discrete variables were analyzed using Chi square tests. A $P$ value of 0.05 or less was considered statistically significant.

\section{Results}

No significant differences were noted between the two groups in age, sex, height, weight, duration of surgery and intraoperative fentanyl dosage (Table 1). In the bupivacaine group, there were seven single lobectomies, one wedge resection and two thoracotomies without lung resection (oesophageal surgery). In the placebo group, there were five single lobectomies, one wedge resection and four thoracotomies without lung resection. In both groups, the degree of lung resection was comparable. Also, the time elapsed from the end of surgery to the first intercostal injection was not different, in the bupivacaine group $16.9 \pm 14.9 \mathrm{~min}$ from the placebo group $24.4 \pm$ $9.2 \mathrm{~min}$.

\section{Pain scores and morphine use}

One hour after the first intercostal injection, both groups of patients showed high VAS pain scores $(7.0 \pm 0.8$ in bupivacaine group versus $8.1 \pm 0.6$ in placebo group). Nevertheless, morphine requirement was less in the bupivacaine group following the first injection, $5.7 \pm 2.7$ $\mathrm{mg}$ (range: $0-28$ ) versus $15.1 \pm 3.4 \mathrm{mg}$ (range: $2-33$ ) in the placebo group $(P<0.05)$ (Figure 2$)$. Two patients in 


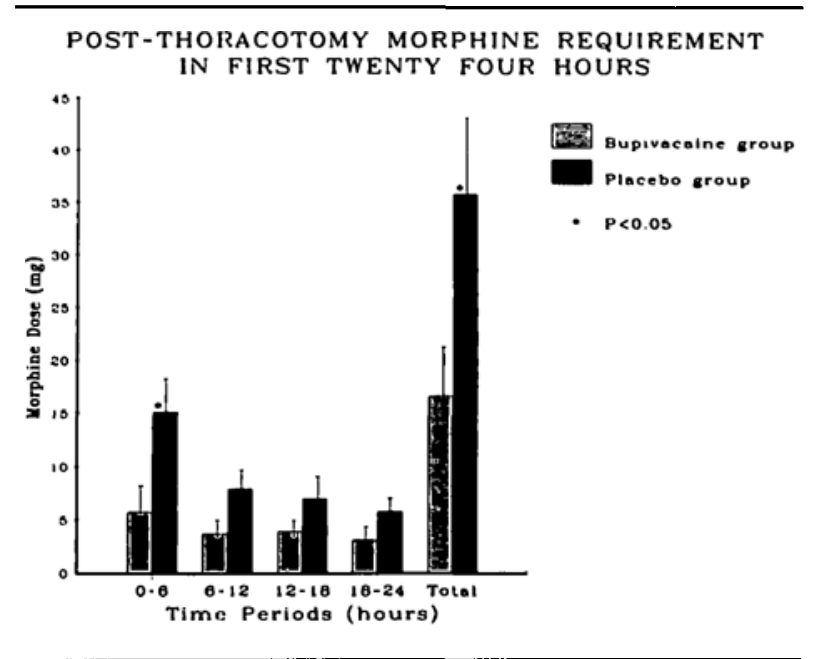

FIGURE 2 Supplemental morphine administration in $24 \mathrm{hr}$ (mean \pm SEM). ${ }^{*} P<0.05$, bupivacaine group versus placebo group.

TABLE II Visual analog pain scores following inlecostal injections (ICI)

\begin{tabular}{|c|c|c|c|c|}
\hline & \multicolumn{2}{|c|}{$\begin{array}{l}\text { Bupivacaine group } \\
(n=10)\end{array}$} & \multicolumn{2}{|c|}{$\begin{array}{l}\text { Placebo group } \\
(n=10)\end{array}$} \\
\hline & Pre & Post & Pre & Post \\
\hline ICI \# I & - & $7.0 \pm 0.8$ & - & $8.1 \pm 0.6$ \\
\hline $\mathrm{ICI} \# 2$ & $5.1 \pm 1.1$ & $2.5 \pm 0.8^{*}$ & $6.2 \pm 0.7$ & $4.6 \pm 1.0$ \\
\hline ICI \#3 & $4.2 \pm 1.0$ & $1.5 \pm 0.8^{*}$ & $4.2 \pm 0.9$ & $3.8 \pm 1.0$ \\
\hline ICI \#4 & $5.5 \pm 1.1$ & $1.5 \pm 0.8^{*}$ & $4.4 \pm 0.8$ & $3.2 \pm 0.8$ \\
\hline
\end{tabular}

Pre $=1$ hour pre-injection; Post $=1$ hour post-injection. Mean \pm SEM.

${ }^{*} P<0.05$, significant difference between pre- and post-injection.

TABLE III Postoperative morphine administration within the Ist $24 \mathrm{hr}$

\begin{tabular}{lcc}
\hline & \multicolumn{2}{c}{ Morphine requirement (mg) } \\
\cline { 2 - 3 } Time interval (hr) & Bupivacaine group & Placebo group \\
\hline $0-6$ & $5.7 \pm 2.67$ & $15.1 \pm 3.40^{*}$ \\
$6-12$ & $3.7 \pm 1.21$ & $7.9 \pm 1.79$ \\
$12-18$ & $3.9 \pm 1.04$ & $7.0 \pm 2.03$ \\
$18-24$ & $3.1 \pm 1.52$ & $5.8 \pm 1.29$ \\
$0-24$, total dose & $16.6 \pm 4.60$ & $35.8 \pm 7.18^{*}$ \\
\hline
\end{tabular}

Mean \pm SEM.

$* P<0.05$, significant difference between groups.

the bupivacaine group did not require any supplemental morphine.

Following the second, third and fourth injections, patients in the bupivacaine group showed a marked decline in their pain score by $50 \%$ or more $(P<0.05$, Table II). This degree of analgesic response was not noted

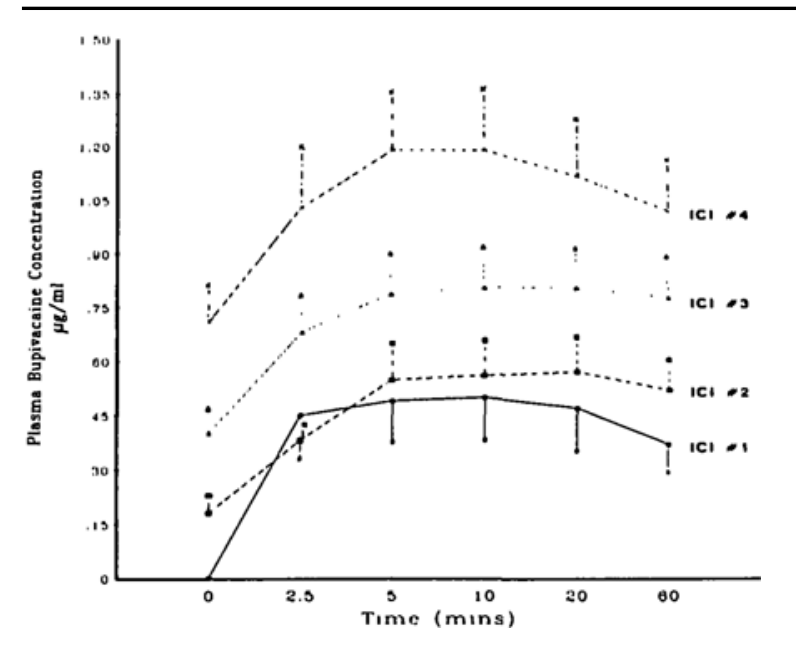

FIGURE 3 Systemic bupivacaine absorption following intercostal injections $(\mathbf{l C l})$.

in the placebo group. Furthermore, the $24 \mathrm{hr}$ morphine requirement in the bupivacaine group was lower, a mean dose of $16.6 \pm 4.6 \mathrm{mg}$ (range: $0-43$ ) versus $35.8 \pm 7.2$ $\mathrm{mg}$ (range: $10-81$ ) in the placebo group $(P<0.05)$ (Table III).

\section{Postoperative pulmonary function assessment}

Preoperative pulmonary function tests showed comparable values of $\mathrm{FEV}_{1}(2.77 \pm 0.17$ vs $2.26 \pm 0.38 \mathrm{~L})$, FVC (3.44 \pm 0.19 vs $3.57 \pm 0.54 \mathrm{~L})$, and PEFR (570.33 \pm 90.16 vs $443.33 \pm 105.12 \mathrm{~L} \cdot \mathrm{min}^{-1}$ ) in both groups (bupivacaine vs placebo). Following thoracotomy, FEV, decreased to $47.4 \pm 6.5 \%$ of the preoperative value in the bupivacaine group versus $29.1 \pm 7.3 \%$ in the placebo group and this difference was not statistically significant. Comparison of FEV, values between the two groups after intercostal injection showed higher values in bupivacaine patients after the second and third intercostal injections $(P<0.01$, Table IV).

The FVC and PEFR in the bupivacaine group decreased to $57.1 \pm 8.2 \%$ and $30.7 \pm 6.1 \%$ of preoperative values while the decline in the placebo group was $37.1 \pm 8.1 \%$ and $28.2 \pm 9.1 \%$ respectively. Higher FVC and PEFR values were also found following the second and third bupivacaine intercostal injection $(P<0.05$, Table IV).

\section{Plasma bupivacaine concentrations}

Systemic accumulation of bupivacaine after repeated intercostal injections is demonstrated in Figure 3. The rapid rise in plasma bupivacaine level peaked within 10-20 min $\left(\mathrm{T}_{\max }\right)$ of each intercostal administration. Mean peak levels $\left(C_{\text {max }}\right)$ following each successive injection were: $0.5 \pm 0.1,0.6 \pm 0.1,0.9 \pm 0.1$, and 1.2 $\pm 0.2 \mu \mathrm{g} \cdot \mathrm{ml}^{-1}$. After a total of $400 \mathrm{mg}$ in $24 \mathrm{hr}$, the 
TABLE IV Pulmonary function tests

\begin{tabular}{|c|c|c|c|c|c|c|c|}
\hline & & \multicolumn{2}{|l|}{$F E V_{1}(L)$} & \multicolumn{2}{|l|}{$F V C(L)$} & \multicolumn{2}{|l|}{$\operatorname{PEFR}\left(L \cdot \min ^{-1}\right)$} \\
\hline & & $\begin{array}{l}\text { Bupivacaine } \\
\text { group }\end{array}$ & $\begin{array}{l}\text { Placebo } \\
\text { group }\end{array}$ & $\begin{array}{l}\text { Bupivacaine } \\
\text { group }\end{array}$ & $\begin{array}{l}\text { Placebo } \\
\text { group }\end{array}$ & $\begin{array}{l}\text { Bupivacaine } \\
\text { group }\end{array}$ & $\begin{array}{l}\text { Placebo } \\
\text { group }\end{array}$ \\
\hline Preop & & $2.77 \pm 0.17$ & $2.26 \pm 0.38$ & $3.44 \pm 0.19$ & $3.57 \pm 0.54$ & $570.33 \pm 90.16$ & $443.33 \pm 105.12$ \\
\hline ICI \#I & $\begin{array}{l}\text { Pre } \\
\text { Pos! }\end{array}$ & $\overline{1.07} \pm 0.19$ & $\overline{0.69} \pm 0.07$ & $\overline{1.36} \pm 0.23$ & $\frac{-}{1.10} \pm 0.05$ & $\overline{150.67 \pm 25.88}$ & $\overline{90.00 \pm 23.62}$ \\
\hline ICI \#2 & $\begin{array}{l}\text { Pre } \\
\text { Post }\end{array}$ & $\begin{array}{l}1.01 \pm 0.18 \\
1.16 \pm 0.11\end{array}$ & $\begin{array}{l}0.64 \pm 0.07 \\
0.68 \pm 0.07 *\end{array}$ & $\begin{array}{l}1.51 \pm 0.29 \\
2.02 \pm 0.37\end{array}$ & $\begin{array}{l}0.97 \pm 0.13 \\
1.09 \pm 0.17^{*}\end{array}$ & $\begin{array}{l}132.67 \pm 21.42 \\
168.70 \pm 21.75\end{array}$ & $\begin{array}{l}101.75 \pm 30.30 \\
106.50 \pm 16.98 *\end{array}$ \\
\hline $\mathrm{ICl} \# 3$ & $\begin{array}{l}\text { Pre } \\
\text { Post }\end{array}$ & $\begin{array}{l}1.13 \pm 0.17 \\
1.22 \pm 0.14\end{array}$ & $\begin{array}{l}0.66 \pm 0.09 \\
0.63 \pm 0.06^{*}\end{array}$ & $\begin{array}{l}1.49 \pm 0.23 \\
1.58 \pm 0.17\end{array}$ & $\begin{array}{l}1.08 \pm 0.12 \\
1.08 \pm 0.10^{*}\end{array}$ & $\begin{array}{l}150.22 \pm 24.53 \\
154.00 \pm 23.78\end{array}$ & $\begin{array}{l}82.71 \pm 15.88 \\
88.12 \pm 12.24 *\end{array}$ \\
\hline $\mathrm{ICl} \# 4$ & $\begin{array}{l}\text { Pre } \\
\text { Post }\end{array}$ & $\begin{array}{l}1.16 \pm 0.17 \\
1.26 \pm 0.18\end{array}$ & $\begin{array}{l}0.77 \pm 0.08 \\
0.87 \pm 0.10\end{array}$ & $\begin{array}{l}1.44 \pm 0.20 \\
1.75 \pm 0.20\end{array}$ & $\begin{array}{l}1.29 \pm 0.03 \\
1.37 \pm 0.06\end{array}$ & $\begin{array}{l}150.89 \pm 21.42 \\
171.30 \pm 30.25\end{array}$ & $\begin{array}{l}130.57 \pm 23.13 \\
144.00 \pm 25.70\end{array}$ \\
\hline
\end{tabular}

$\mathrm{ICl}=$ Intercostal injection; Pre $=\mathrm{I}$ hour pre-injection, PosI $=\mathrm{I}$ hour post injection

Mean \pm SEM.

$* P<0.05$, significant difference between groups in posl-injection tests.

plasma bupivacaine level was still below toxic range (4 $\left.\mu \mathrm{g} \cdot \mathrm{ml}^{-1}\right) .{ }^{9}$ No cardiovascular or neurological complication as a result of intercostal bupivacaine injection was noted in this study.

\section{Discussion}

To maintain effective long-lasting analgesia, conventional intercostal nerve block needs to be repeated. Each time this is accompanied by the discomfort of patient positioning and multiple needle punctures at intercostal spaces adjacent to the incision site. In practice, a continuous technique allows repeated local anaesthetic administration without undue patient trauma and discomfort. For non-thoracotomy incisions, a blind percutaneous technique is used to insert an intercostal catheter (epidural catheter) into a single posterior intercostal space. ${ }^{4}$ Despite initial controversy of the extent of local anaesthetic spreading within the intercostal space after a bolus injection, ${ }^{10}$ the accumulated evidence has now confirmed that anaesthesia and analgesia can be achieved in multiple dermatomes following a $20 \mathrm{ml}$ bolus injection at a single intercostal level. ${ }^{11-13}$ Spreading of local anaesthetic following a bolus injection may be achieved via the subpleural, para-vertebral or epidural spaces.

For thoracotomy incisions, this situation is unique in that a catheter can be placed, under direct vision, into the desired intercostal space with precision and with minimal trauma before chest wall closure. In our experience, this simple procedure can be accomplished within 5-10 min. Correct placement into the posterior intercostal spaces can be confirmed by visual inspection and by palpation. Using this technique, unintentional subarachnoid injection is unlikely because catheters are placed $7-8 \mathrm{~cm}$ from the posterior midline. Intercostal catheterization has advantages over interpleural catheterization. There is no diffusion barrier, parietal pleura, for the local anaesthetic agent to overcome. In addition, local anaesthetic has direct access to the intercostal nerves without being diluted by fluids in the pleural cavity.

Successful analgesia from this method of intercostal catheterization appears to depend on two factors: the ease of catheter insertion and the integrity of the parietal pleura under which the catheter is tunnelled. Unfavourable factors such as pleural adhesions preclude proper access to the posterior intercostal spaces and torn parietal pleura allows local anaesthetic leakage from the injection sites. Analgesic failure due to torn parietal pleura has been described. ${ }^{14}$

Although the technique of continuous intercostal nerve block to control post-thoracotomy pain has been previously described, ${ }^{14-16}$ detailed objective assessments on analgesic response and postoperative pulmonary function have been lacking. Also, in these previous studies, there were variations in the number of catheters placed (from one to four), in the choice of local anaesthetic (bupivacaine or lidocaine) and in the injection technique (intermittent bolus versus continuous infusion). In the present study, we chose to place two intercostal catheters, one above and one below the incision site. This was based on the assumption that the spread of local anaesthetic across the incision site may be unreliable.

Despite a small sample size of 20 patients, the analgesic effect of continuous intercostal nerve block to control post-thoracotomy pain was clearly demonstrated. Following bupivacaine, decreases in VAS and morphine requirement were highly significant. The reason for high VAS 
score one hour after the initial bupivacaine injection is unclear. However, analgesia from the initial dose was no doubt effective because the need for supplemental morphine during this period was less (Figure 2).

Although effective, analgesia appeared to be incomplete since morphine supplementation was given to most patients in the bupivacaine group. Our results did not show the same degree of success as in Sabanathan's study which reported complete analgesia in 93\% (75/81) of patients for $24 \mathrm{hr} .{ }^{14}$ Unfortunately, the pain score was not documented in that study. There are several possible explanations for the incomplete analgesia and morphine supplementation in our patients: (I) Intercostal nerve block does not intercept all components of postthoracotomy pain: unblocked pain impulses may arise from diaphragmatic pleura which is innervated by the phrenic nerve, the mediastinum which is innervated by the vagus nerve, and damaged muscular and ligamentous structures in the periscapular, paravertebral side of the thoracotomy incision which is innervated by the posterior division of the appropriate spinal nerve. ${ }^{17}$ (2) The double-blind design did not forbid narcotic supplementation in either patient group. Our results showed striking similarity in the amount of supplemental morphine required in the treatment and placebo groups as reported in Shulman's double-blind study on epidural morphine for post-thoracotomy pain. ${ }^{18}$ (3) A difference in dose and technique of bupivacaine administration: intermittent injection of $100 \mathrm{mg}$ at six hourly intervals in this study versus continuous infusion of a higher dose, 25-35 $\mathrm{mg} \cdot \mathrm{hr}^{-1}$ (150-210 $\mathrm{mg}$ per six hours).

Deterioration in pulmonary function following thoracotomy can be attributed in part to incisional pain, which induces splinting of intercostal muscles, ${ }^{19,20}$ and in part to a loss of lung parenchyma from surgical resection. ${ }^{21} \mathrm{By}$ controlling incisional pain, conventional intercostal nerve block has been shown to improve FEV,${ }^{22,23} \mathrm{FVC}^{22,24,25}$ and PEFR ${ }^{23,24,26}$ following thoracotomy. However, one would not expect to see beneficial pulmonary effects to last beyond the duration of local anaesthetic activity from a single dose unless repeated injections are given. This study demonstrated clearly that prolonged analgesia and improved pulmonary function can be obtained from repeated bupivacaine injections through two indwelling intercostal catheters (Table IV).

In this study, we chose regular intermittent bolus injections every six hours and not "on demand." The selection of $100 \mathrm{mg}$ bupivacaine per intercostal injection was guided by results of several previous studies. $6,11,27$ The duration of analgesia was found to be six to seven hours for cholecystectomy patients. ${ }^{6}$ Among the regional blocks commonly practiced, intercostal nerve block results in the highest systemic absorption of local anaes- thetic. In the absence of data on systemic accumulation after repeated injections, we were conservative in restricting the $24 \mathrm{hr}$ bupivacaine administration to $400 \mathrm{mg}$ for fear of potential toxic drug reactions. For a $100 \mathrm{mg}$ dose of bupivacaine with epinephrine injected intercostally, the plasma concentration reached a peak of $0.82 \mu \mathrm{g} \cdot \mathrm{ml}^{-1}$ in 5-10 min. ${ }^{28}$ In this study, we found a slightly lower concentration $0.5 \pm 0.13 \mu \mathrm{g} \cdot \mathrm{ml}^{-1}$ after the initial $100 \mathrm{mg}$ bolus. Even after the fourth bolus, the peak level was 1.2 $\pm 0.2 \mu \mathrm{g} \cdot \mathrm{ml}^{-1}$ which is lower than the toxic threshhold $\left(4 \mu \mathrm{g} \cdot \mathrm{ml}^{-1}\right){ }^{9}$ We did not observe any cardiovascular or neurological side-effect from this technique of continuous intercostal bupivacaine administration.

We conclude that continuous intercostal nerve block by repeated bupivacaine injections following thoracotomy offers satisfactory pain relief, improvement in pulmonary function, and safe, non-toxic plasma bupivacaine concentrations. However, the long-term efficacy and safety of this technique beyond $24 \mathrm{hr}$ of treatment needs further elucidation.

\section{Acknowledgment}

The authors wish to thank Miss Christine Drane for her secretarial assistance.

\section{References}

1 Moore $D C$, Bridenbaugh $L D$. Intercostal nerve block in 4333 patients: indications, technique, and complications. Anesth Analg 1962; 41: 1-11.

2 Bridenbaugh PO, DuPen SL, Moore DC et al. Postoperative intercostal nerve block analgesia versus narcotic analgesia. Anesth Analg 1973; 52: 81-5.

3 O' Kelly E, Garry B. Continuous pain relief for multiple fractured ribs. Br J Anaesth 1981; 53: 989-91.

4 Murphy $D F$. Continuous intercostal nerve blockade for pain relief following cholecystectomy. Br J Anaesth 1983; 55: 521-4.

5 Baxter $A D$, Jennings FO, Harris $R S$, Flynn $J F$, Way $J$. Continuous intercostal blockade after cardiac surgery. Br Anaesth 1987; 59: 162-6.

6 Murphy $D F$. Intercostal nerve blockade for fractured ribs and postoperative analgesia: description of a new technique. Regional Anesthesia 1983; 8: 151-3.

7 Mowbray A, Wong KKS, Murray JM. Intercostal catheterisation: an alternative approach to the paravertebral space. Anaesthesia 1987; 42: 958-61.

8 Tucker GT. Determination of bupivacaine (marcaine) and other anilide-type local anesthetics in human blood and plasma by gas chromatography. Anesthesiology 1970; 32: 255-60.

9 Cousins MJ, Bridenbaugh PO. Neural blockade in clinical anesthesia and management of pain. Philadelphia:

Lippincott, 1988; 122. 
10 Moore $D C$. Intercostal nerve block: spread of india ink injected to the rib's costal groove. Br J Anaesth 1981; 53: 325-9.

II Murphy DF. Continuous intercostal nerve blockade: an anatomical study to elucidate its mode of action. $\mathrm{Br} \mathrm{J}$ Anaesth 1984; 56: 627-9.

12 Middaugh RE, Menk EJ, Reynolds WJ, Bauman JM, Cawthon MA, Hartshorne MF. Epidural block using large volumes of local anesthetic solution for intercostal nerve block. Anesthesiology 1985; 63: 214-6.

13 Crossley AWA, Hosie HE. Radiographic study of intercostal nerve blockade in healthy volunteers. $\mathrm{Br} \mathrm{J}$ Anaesth 1987; 59: 149-54.

14 Sabanathan S, Bickford Smith PJ, Pradhan GN, Hashimi $H$, Eng JB, Mearns AJ. Continuous intercostal nerve block for pain relief after thoracotomy. Ann Thorac Surg 1988; 46: 425-6.

15 Olivet RT, Nauss LA, Payne WS. A technique for continuous intercostal nerve block analgesia following thoracotomy. Thorac Cardiovasc Surg 1980; 80: 308-11.

16 Safran D, Kuhlman G, Orham EE, Castelain $M H$, Journois $D$. Continuous intercostal blockade with lidocaine after thoracic surgery. Anesth Analg 1990; 70: 345-9.

17 Conacher ID. Pain relief after thoracotomy. Br J Anaesth 1990; 65: 806-12.

18 Shulman M, Sandler AN, Bradley JW, Young PS, Brebner $J$. Postthoracotomy pain and pulmonary function following epidural and systemic morphine. Anesthesiology 1984; 61: 569-75.

19 Johnson WC. Postoperative ventilatory performance: dependence upon surgical incision. Am Surg 1975; Oct.: 615-9.

20 Craig DB. Postoperative recovery of pulmonary function. Anesth Analg 1981; 60: 46-52.

21 Berend N, Woolcock AJ, Marlin GE. Effects of lobectomy on lung function. Thorax 1980; 35: 145-50.

22 Toledo-Pereyra LH, DeMeester TR. Prospective randomized evaluation of intrathoracic intercostal nerve block with bupivacaine on postoperative ventilatory function. Ann Thorac Surg 1979; 27: 203-5.

23 Delilkan AE, Lee CK, Yong NK, Ong SC, Ganendran $A$. Postoperative local analgesia for thoracotomy with direct bupivacaine intercostal blocks. Anaesthesia 1973; 28: $561-7$.

24 Kaplan JA, Miller ED, Gallagher EG. Postoperative analgesia for thoracotomy patients. Anesth Analg 1975; 54: 773-7.

25 Faust RJ, Nauss LA. Post-thoracotomy intercostal block: comparison of its effects on pulmonary function with those of intramuscular meperidine. Anesth Analg 1976; 55 : 542-6.
26 Bergh NP, Dottori O, Lof BA, Simonsson BG, Ygge $H$. Effect of intercostal block on lung function after thoracotomy. Acta Anaesthesiol Scand, Suppl 1966; 24: 85-95.

27 Lyles R, Skurdal D, Stene J, Jaberi M. Continuous intercostal catheter techniques for treatment of posttraumatic thoracic pain. Anesthesiology 1986; 65: A205.

28 Moore DC, Mather LE, Bridenbaugh LD, Balfour RI, Lysons $D F$, Horton WG. Arterial and venous plasma levels of bupivacaine following peripheral nerve blocks. Anesth Analg 1976; 55: 763-8. 